\title{
Flood Forecasting Based on TIGGE Precipitation Ensemble Forecast
}

\author{
Jinyin Ye, ${ }^{1}$ Yuehong Shao, ${ }^{2}$ and Zhijia $\mathrm{Li}^{3}$ \\ ${ }^{1}$ Huaihe Meteorological Center, Hefei 230031, China \\ ${ }^{2}$ Nanjing University of Information Science and Technology, Nanjing 210044, China \\ ${ }^{3}$ College of Hydrology and Water Resources, Hohai University, Nanjing 210098, China \\ Correspondence should be addressed to Jinyin Ye; yejinyin@sina.com
}

Received 17 July 2016; Revised 16 October 2016; Accepted 6 November 2016

Academic Editor: Anthony R. Lupo

Copyright (c) 2016 Jinyin Ye et al. This is an open access article distributed under the Creative Commons Attribution License, which permits unrestricted use, distribution, and reproduction in any medium, provided the original work is properly cited.

TIGGE (THORPEX International Grand Global Ensemble) was a major part of the THORPEX (Observing System Research and Predictability Experiment). It integrates ensemble precipitation products from all the major forecast centers in the world and provides systematic evaluation on the multimodel ensemble prediction system. Development of meteorologic-hydrologic coupled flood forecasting model and early warning model based on the TIGGE precipitation ensemble forecast can provide flood probability forecast, extend the lead time of the flood forecast, and gain more time for decision-makers to make the right decision. In this study, precipitation ensemble forecast products from ECMWF, NCEP, and CMA are used to drive distributed hydrologic model TOPX. We focus on Yi River catchment and aim to build a flood forecast and early warning system. The results show that the meteorologichydrologic coupled model can satisfactorily predict the flow-process of four flood events. The predicted occurrence time of peak discharges is close to the observations. However, the magnitude of the peak discharges is significantly different due to various performances of the ensemble prediction systems. The coupled forecasting model can accurately predict occurrence of the peak time and the corresponding risk probability of peak discharge based on the probability distribution of peak time and flood warning, which can provide users a strong theoretical foundation and valuable information as a promising new approach.

\section{Introduction}

Flood forecasting is one of the major bases for decisionmakers to deal with an emergency situation associated with heavy rainfall. Precipitation is the most important information required for flood forecasting. The accuracy and the lead time are two major factors influencing the performance of the flood forecasting [1]. Application of precipitation forecast products from numerical weather prediction (NWP) on flood forecasting is one of the primary ways to extend the lead time of a flood forecast. The NWP makes it possible to generate useful flood information and issue an early warning of flood. However, due to the errors associated with initial condition and model, the chaos of the atmosphere, and the uncertainties of parameterization as well as the heterogeneousness of the underlying surface, there are large discrepancies between the "single" deterministic flood forecast and the observations, especially for the outburst of local meteorological and hydrological events [2]. To overcome the limit of the deterministic forecast, people start to focus on the uncertainty of the meteorological and hydrological processes. The traditional "single" deterministic forecast is gradually replaced by the probability forecast which represents the uncertainty of the forecast, that is, a transition from deterministic forecast to ensemble forecast. As a new technique of NWP, ensemble forecast considers the influences from the imperfect boundary conditions and data assimilation, turning the deterministic forecast to complete probability forecast of atmospheric variables [3]. It is a new approach for precipitation forecast and runoff forecast [4].

To account for the uncertainties of the forecasts from multiple global models, an interactive grand global ensemble system was proposed. TIGGE (THORPEX International Grand Global Ensemble) is an international scientific project collecting forecast products from all the major forecast centers in the world and evaluating the multiple model 
ensemble system [5]. TIGGE ensemble forecast combines the uncertainties from multiple sources and represents those uncertainties with probability distribution. It has already been applied on flood forecasting and early warning of flood with successful results. Pappenberger et al. [6] coupled TIGGE ensemble data with $5 \mathrm{~km}$ distributed hydrologic model and successfully produced early warning for flood with a lead time of 10 days. He et al. [7, 8] used TIGGE ensemble forecasts to drive an atmospheric-hydrologic-hydraulic cascade system to produce a probabilistic discharge forecast and early flood warning. Peng et al. [9] used ECMWF ensemble forecast to drive Xinanjiang hydrologic model (hereafter XAJ model) and, by forecasting range of the runoff, provided useful risk information to decision-maker. However, the last research work only considered ECMWF model; uncertainties from multiple models and multiple forecast centers are not involved. Precipitation ensemble forecasts from four major forecast centers were used to make superensemble forecast and early flood warning; the results are encouraging [10, 11]. For most studies in China, they adopted aggregated approach with XAJ model and did not consider the influence from heterogeneous underlying surface. On the basis of the improved SIMTOP (a simple TOPMODEL) runoff parameterization scheme and the calculating method of three-layer soil moisture balance in Xinanjiang model, Yong (2008) developed a simple but highly-efficient large-scale hydrological model (TOPX). The offline test performed at Youshui River catchment (a small branch of Yangtze River) indicated that the TOPX model produced better simulation effect of daily runoff in small sized catchments and it can describe the various hydrological processes of watershed [12]. In this study, we focus on Yishu River catchment (upstream catchment of Linyi hydrologic station). ECMWF (50 ensemble members), NCEP (20 ensemble members), and CMA (15 ensemble members) ensemble precipitation data were used to drive the distributed hydrologic model TOPX to make flood forecast and early flood warning.

\section{About the Catchment}

The research area in this study includes the upstream catchment of Yishu River (i.e., Linyi subsystem) with a catchment size of $10152 \mathrm{~km}^{2}$. It has a typical continent monsoon climate with four distinct seasons. It is hot in summer with a lot of rainy days and cold and windy in winter. There is an uneventful terrain with elevation ranging from $57 \mathrm{~m}$ to $1125 \mathrm{~m}$. The mean annual temperature is $11.8^{\circ} \mathrm{C}-13.3^{\circ} \mathrm{C}$ and mean annual precipitation/evaporation amount is $830 \mathrm{~mm} / 839 \mathrm{~mm}$ with most of precipitation fall in summer in a form of heavy rainfall. There is also significant interannual variation of the precipitation.

\section{Construction of Flood Forecast Model Based on TIGGE Ensemble Precipitation Forecast}

3.1. Introduction to TOPX. TOPX is a land-surface model developed based on improved SIMTOP (a simple TOPMODEL) and XAJ model. It incorporates both the topographic index concept from TOPMODEL and the water budget balance principle and is able to capture the land-surface hydrologic processes with a linear scaling transformation scheme for topographic index [12].

The model has seven major components including storage capacity curve, dynamic change of soil moisture, simulated surface runoff and subsurface runoff, simulated discharge, base discharge, Muskingum merge flow, and evaluation factor. TOPX can provide the function of scaling transformation on topographic index. Although the TOPX model has less data input and minimum parameters for calibrating, it can better describe the two-dimensional hydrological processes. The detailed introduction about the model can be found in Yong (2008) and Shao [13]. In the following, we will only introduce the generation and concentration of the runoff as well as the dynamic changes of soil water.

(1) Runoff Generation Formula. A revised SIMTOP runoff generation scheme including the generation of both surface runoff and subsurface runoff is adopted in this study. The formula is shown below:

$$
\begin{aligned}
R_{\mathrm{s}} & =F_{\max } e^{-C_{\mathrm{s}} z_{\nabla}} Q_{\mathrm{wat}}, \\
R_{\mathrm{sb}} & =R_{\mathrm{sb}, \text { max }} e^{-f z_{\nabla}},
\end{aligned}
$$

where $R_{\mathrm{s}}$ is surface runoff, $R_{\mathrm{sb}}$ is subsurface runoff, $F_{\max }$ is percentage of the maximum saturated area, $R_{\mathrm{sb}, \max }$ is the maximum subsurface runoff when the soil moisture deficit depth is $0, Q_{\text {wat }}$ is net precipitation, $z_{\nabla}$ is average water depth, $f$ is decaying parameter of soil, and $C_{s}$ is a coefficient that can be derived by fitting the exponential function to the discrete cumulative distribution function (CDF) of the topographic index $\lambda_{\mathrm{m}}$. The computational approach to $C_{\mathrm{s}}$ and $\lambda_{\mathrm{m}}$ can be found in the work of Niu et al. [14]. The revised SIMTOP scheme can represent the topographic information more accurately and produce more realistic temporal-spatial distribution of variables and parameters.

(2) Calculation of Soil Moisture. Soil moisture deficit is a crucial variable connecting surface runoff and subsurface runoff, and it is closely related to the budget of the soil moisture. This formula is developed based on three-layer soil evapotranspiration scheme from XAJ model, and it can significantly simplify the calculation of the soil moisture deficit without reducing the accuracy required by the model [15]. After the temporal-spatial distribution of soil moisture is obtained from the three-layer evapotranspiration formula, the soil moisture deficit thus can be estimated from the difference of the average storage capacity and soil moisture, and finally the surface runoff and subsurface runoff will be calculated. The formula is shown below:

$$
z_{\nabla}=\mathrm{WM}-W[i]
$$

where WM is the areal mean tension water capacity which has three components WU, WL, and WD in the upper, lower, and 
TABLE 1: Some major parameters in TOPX model with calibration results.

\begin{tabular}{|c|c|c|c|c|}
\hline Parameter name & Physical meaning & Parameter type & Calibration (20010729) & Calibration (20020722) \\
\hline$f$ & Decaying parameter & \multirow{4}{*}{$\begin{array}{l}\text { Runoff generation } \\
\text { parameters }\end{array}$} & 180 & 180 \\
\hline$G_{\max }$ & Maximum underground runoff & & 50 & 50 \\
\hline KSS & $\begin{array}{l}\text { Outflow coefficient of free water storage } \\
\text { to interflow relationship }\end{array}$ & & 0.012 & 0.012 \\
\hline$B$ & $\begin{array}{l}\text { Exponential of the distribution to tension } \\
\text { water capacity }\end{array}$ & & 0.40 & 0.35 \\
\hline$K$ & $\begin{array}{c}\text { Ratio of potential evapotranspiration to } \\
\text { pan evaporation }\end{array}$ & \multirow{5}{*}{$\begin{array}{l}\text { Soil moisture } \\
\text { calculation }\end{array}$} & 0.85 & 0.85 \\
\hline WM & Averaged soil moisture storage capacity & & 125.0 & 125.0 \\
\hline WUM & $\begin{array}{c}\text { Averaged soil moisture storage capacity of } \\
\text { upper layer }\end{array}$ & & 30.0 & 30.0 \\
\hline WLM & $\begin{array}{c}\text { Averaged soil moisture storage capacity of } \\
\text { lower layer }\end{array}$ & & 90.0 & 90.0 \\
\hline C & $\begin{array}{c}\text { Evapotranspiration coefficient of deep } \\
\text { layer }\end{array}$ & & 0.12 & 0.12 \\
\hline KKG & $\begin{array}{c}\text { Recession constants of the ground water } \\
\text { storage }\end{array}$ & \multirow{2}{*}{$\begin{array}{l}\text { Runoff concentration } \\
\text { parameters }\end{array}$} & 0.988 & 0.988 \\
\hline $\mathrm{UH}$ & Initial value of unit hydrograph & & $\begin{array}{c}/ 0,44.6,156,86.7,39 \\
22.3,15.6 /\end{array}$ & $\begin{array}{l}/ 0,12,42,23,3,10.5 \\
6.0,4.2 /\end{array}$ \\
\hline
\end{tabular}

deep layer, respectively, and $W[i]$ is the sum of three-layer soil moisture of the $i$ th day.

(3) Runoff Concentration. There are three components in TOPX model: overland flow concentration, river network flow, and subsurface flow concentration. Three different methods including empirical unit hydrograph method, Muskingum channel routing method, and linear reservoir parameter method are applied to calculate these three components, respectively, and finally the outlet runoff is obtained.

3.2. TIGGE Precipitation Ensemble Coupled with TOPX. As one of the primary international scientific projects, THORPEX aims to contribute to our society, economics, and environment by advancing a unified observation-forecast system and improving the accuracy of 1-14 days' high impact weather forecast. TIGGE, as the core component of the THORPEX, aggregates the forecast products from all major forecast centers in the world and provides further analyzing, processing, and evaluation support to users. All the forecast centers started to receive and share the corresponding TIGGE data, which provides an opportunity for developing a flood forecast model based on coupling TIGGE data and hydrologic model. NCEP, ECMWF, and CMA ensemble forecast data from TIGGE project are used in this study; the horizontal resolutions for these forecast data are $1^{\circ} \times 1^{\circ}, 0.5^{\circ} \times 0.5^{\circ}$, and $0.5625^{\circ} \times 0.5625^{\circ}$, respectively. Because of different resolution for these three forecast data, 12, 25, and 20 grid points are used to cover the area we are interested in (Figure 1). Also inverse distance weighting (IDW) method and Kriging method are adopted to downscale the 6-hour accumulated precipitation forecast from different ensemble dataset into $1 \mathrm{~km}$ to drive the hydrologic model. Hereafter, the TOPX coupled with ECMWF, NCEP, and CMA ensemble precipitation forecast is called ECMWF-TOPX, NCEP-TOPX, and CMATOPX, respectively.

According to the hydrological and metrological data, 12 flood events are selected for this study. The simulation starts from the time when the precipitation occurred and ends after the flood retreated with a time step of 6 hours. The model parameters are calibrated with 6 flood events during 2001-2004. The calibrated parameters from two of these typical events are then used in simulation of another 6 flood events during 2005-2008. Some major parameters in TOPX hydrologic model as well as their physical meanings are showed in Table 1 . The calibrated model parameters from 20010729 event are used to verify three predicted floods with TIGGE data during 2007-2008. Due to similarity of the discharge magnitude between 2010 and 2002, one of the flood forecast in 2010 is verified with calibrated model parameters from 20020722 event.

\section{Verification of Flood Forecast in Yi River Catchment}

4.1. Results of TIGGE Precipitation Ensemble Forecast. Accuracy of the precipitation forecast directly influences the performance of the model forecast. Therefore, it is necessary to evaluate the TIGGE precipitation ensemble forecast first. We compared ECMWF, NCEP, and CMA ensemble forecasts, and the multimodel precipitation ensemble is also verified with observations. Four heavy rainfall events including 20070809, 20070815, 20080720, and 20100716 are selected to evaluate TIGGE precipitation forecast. Figure 2 shows the precipitation forecast from ECMWF, NCEP, and CMA ensemble forecasts as well as the verification against observations. Non-real-time update means only the 10-day 

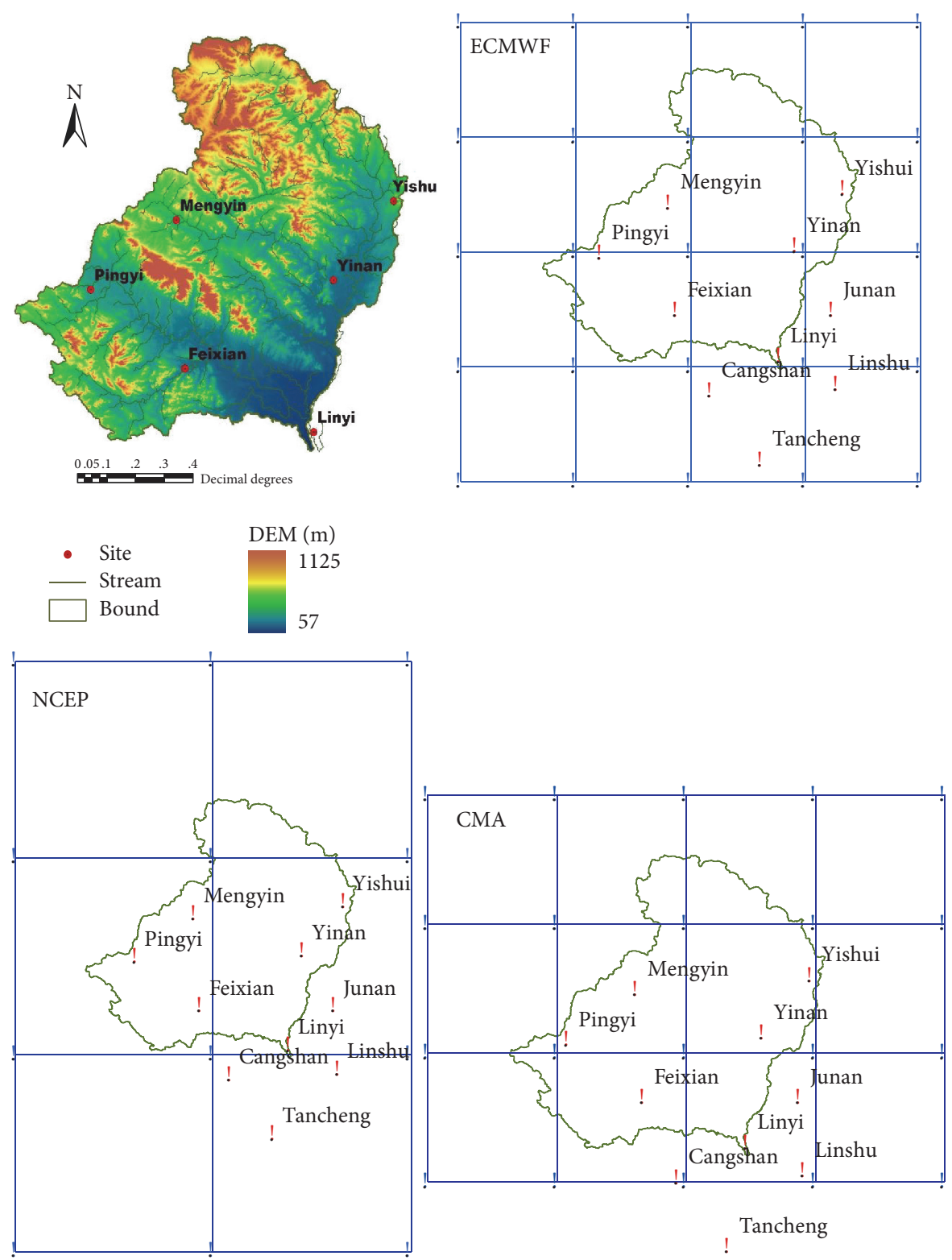

FIGURE 1: Distribution of stations, catchments, and the selected grid points in ECMWF, NCEP, and CMA ensemble models.

precipitation forecast is used, and real-time update means daily precipitation forecast is used. Figure 2 shows clearly the remarkable differences among those three ensemble forecasts. NCEP forecasted less precipitation than observations with substantial smaller maximum precipitation. The precipitation forecast in CMA ensemble products is much larger than observations, with large discrepancy in forecasted time of occurrence of heavy rainfall. Also, the spread of ensemble members is also much larger than that in other ensemble forecasts.

4.2. Discharge Forecasts over Yi River Catchment. Figure 3 shows the forecasted discharges based on three different precipitation ensemble forecasts for 20070809 event. It can be noticed that the peak discharge as well as the time of occurrence can be well predicted by all the three ensemble forecasts. However, there are large errors for the magnitude of forecasted discharges. CMA-TOPX obviously forecasted much larger amount of discharges, while NCEP-TOPX forecasted much smaller amount instead. Only ECMWF-TOPX forecasted discharges are relatively close to the observations. The results for the other three events are similar; ECMWFTOPX forecasted discharges are always the best among them. Because the runoff generation scheme is better for humid area, for those events (e.g., 20100706 event) with less amount of runoff, the simulation results are not good. There are large discrepancies among the three ensembles; the forecasted discharges as well as time of occurrence all significantly deviate from the observations. Nevertheless, if we use all the 85 ensemble members to drive the TOPX, we can obtain 

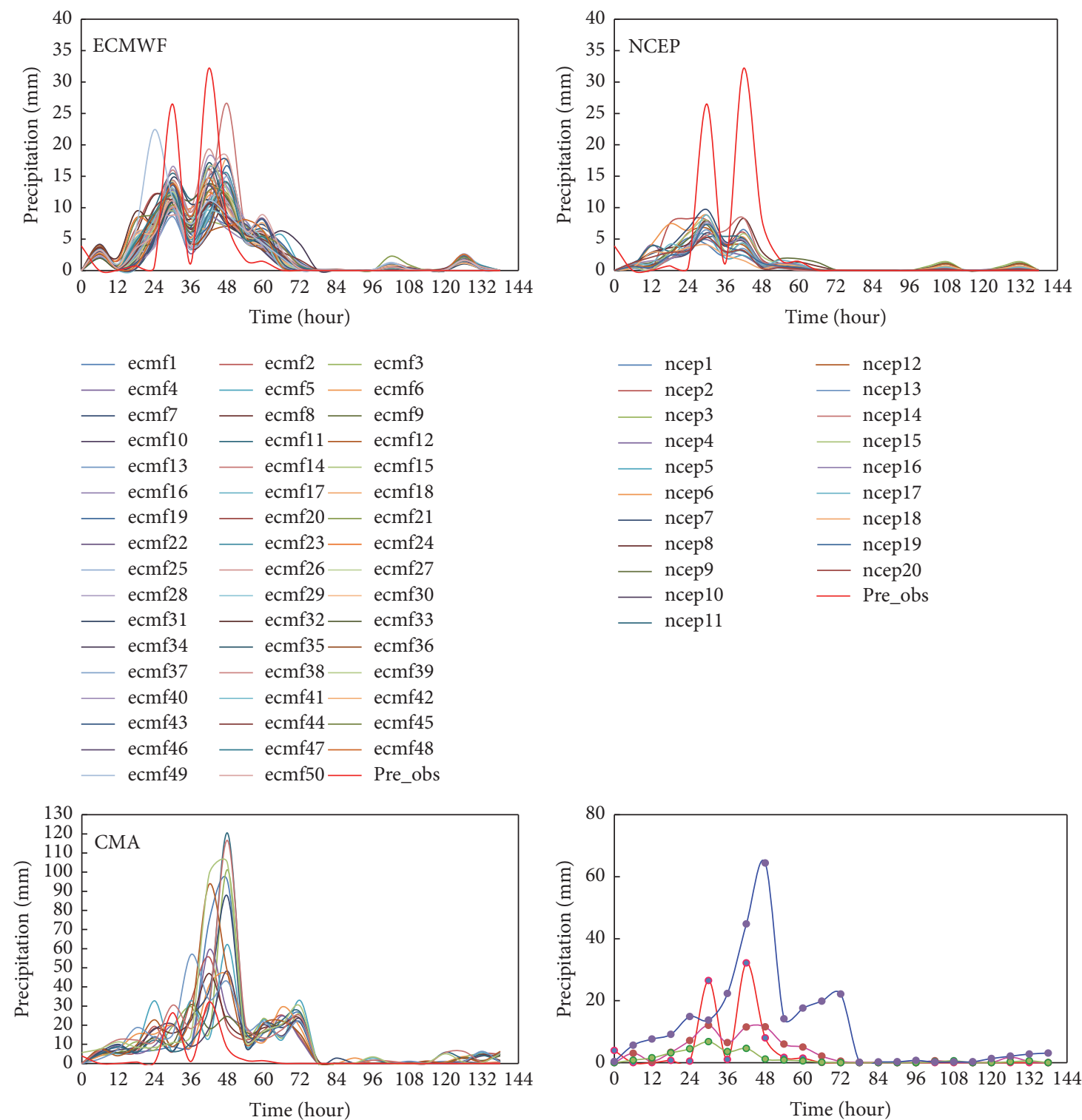

$\begin{array}{ll}\text { - babj1 } & - \text { babj9 } \\ \text { - babj2 } & - \text { babj10 } \\ \text { babj3 } & - \text { babj11 } \\ \text { - babj4 } & - \text { babj12 } \\ \text { babj5 } & - \text { babj13 } \\ \text { babj6 } & - \text { babj14 } \\ \text { - babj7 } & \text { - babj15 } \\ \text { babj8 } & \text { - Pre_obs }\end{array}$

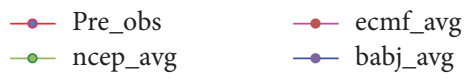

Figure 2: Comparison of the predicted precipitation (20070809 event) from ECMWF, NCEP, and CMA ensemble models.

superensemble forecasts (figure not shown). Superensemble forecasts can provide comprehensive information including the range and the probability distribution of forecasted discharges, as well as the superensemble mean of all 85 members. For example, for the 20070809 event, the probability of discharge larger than $2000 \mathrm{~m}^{3} / \mathrm{s}$ and $1000 \mathrm{~m}^{3} / \mathrm{s}$ is $35.3 \%$ and $69.4 \%$, respectively. The users can respond to the forecasted probability accordingly.
Figure 4 shows the ensemble mean discharges from ECMWF-TOPX, NCEP-TOPX, and CMA-TOPX models. It is obvious that the forecasted peak discharges and the time of occurrence are close to the observations. However, large variabilities exist for the forecasted magnitudes of the peak discharges. It can be seen that the ECMWF-TOPX has the closest magnitude to the observations for the 20070809 event, which is probably related to the fact that it has 

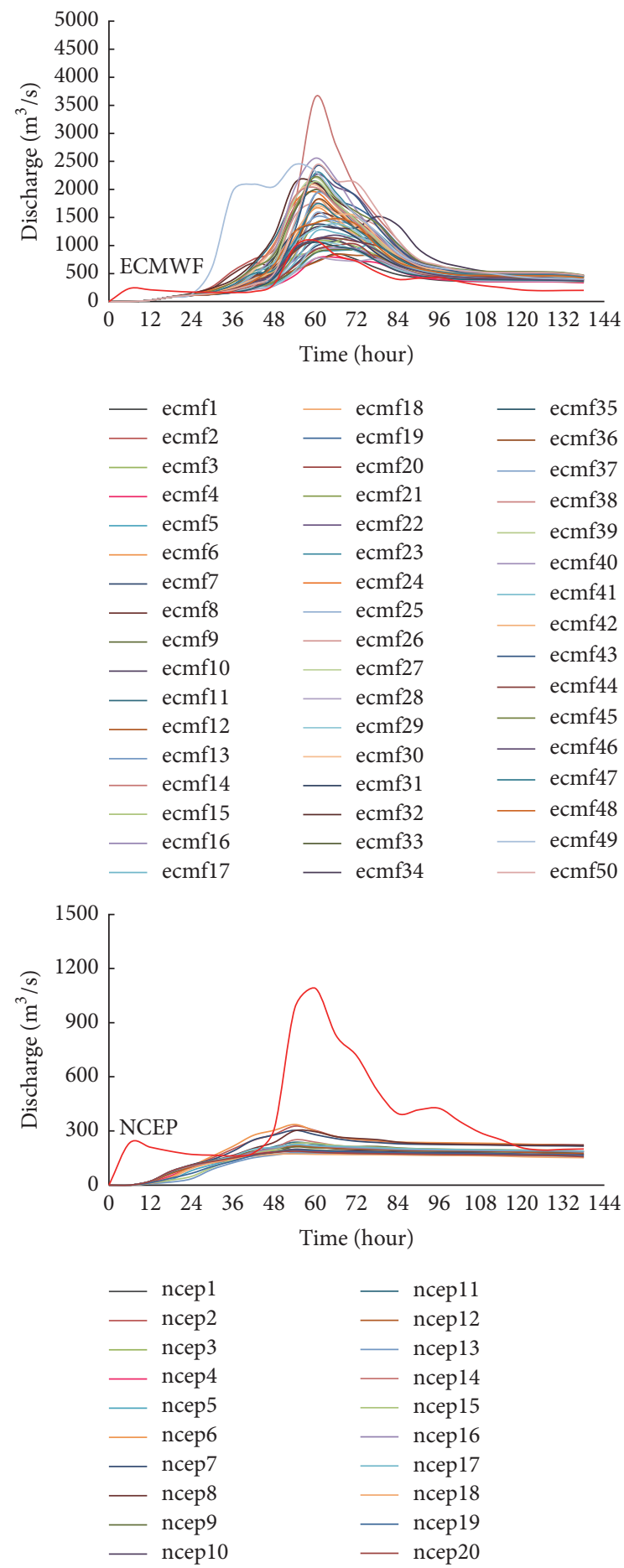
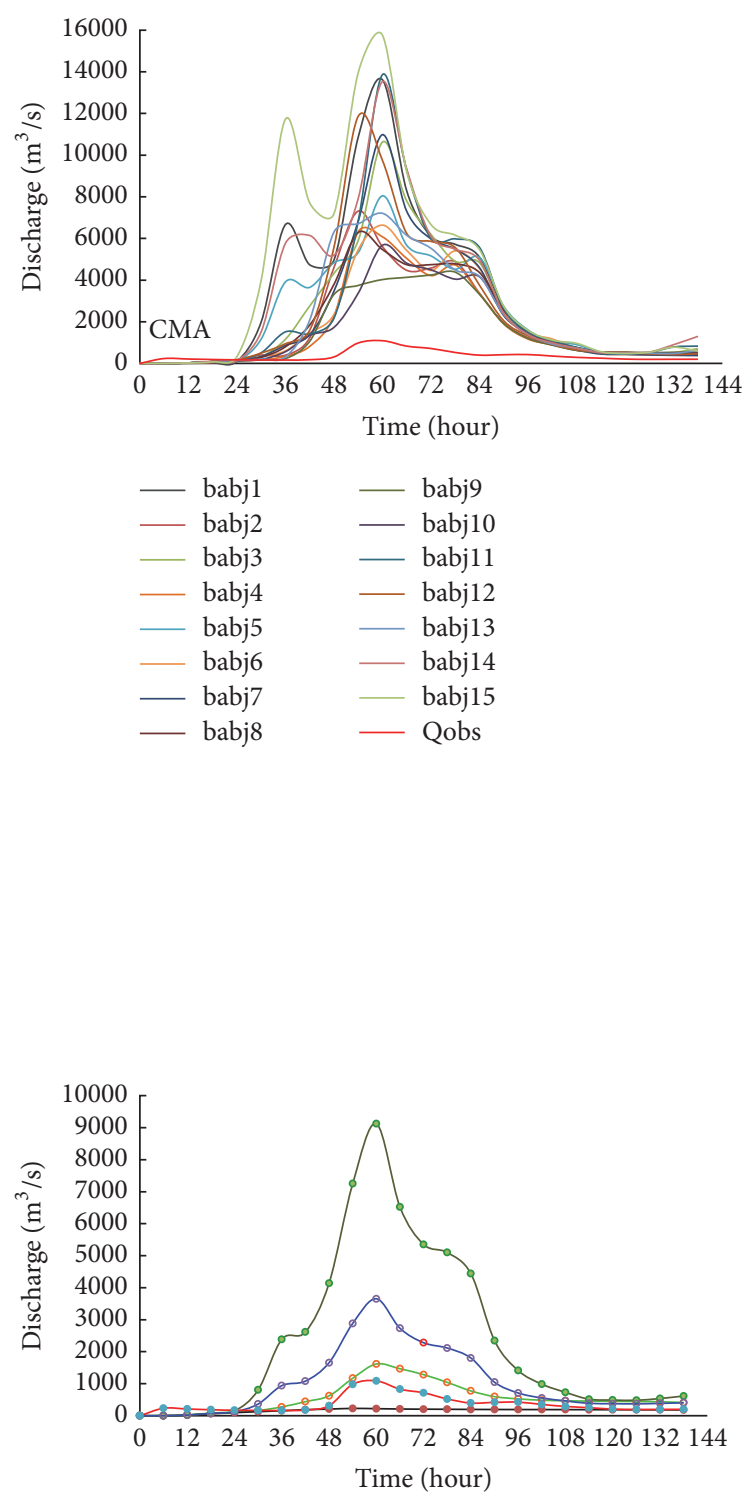

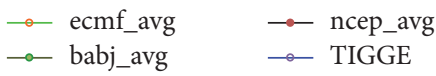

Figure 3: Same with Figure 2 except for forecasted discharges.

the most ensemble members (50). For all the other three events, the superensemble is the best. The NCEP-TOPX has the minimum ensemble mean discharge, while the CMATOPX ensemble mean discharge has the maximum ensemble mean discharge due to the largest amount of forecasted precipitation. In general, these three coupled systems can all predict the occurrence time of peak discharge, but significant forecast errors still exist for the magnitude of discharge, especially for NCEP-TOPX and CMA-TOPX, which is due to less/more forecasted precipitation. The challenges for later research are how we can improve the accuracy of peak discharge by calibrating the ensemble precipitation forecasts from different forecast centers and how we set different weights for different ensemble systems.

Figure 5 shows the occurrence of peak discharge probability distribution for the $20070809,20070815,20080720$, and 

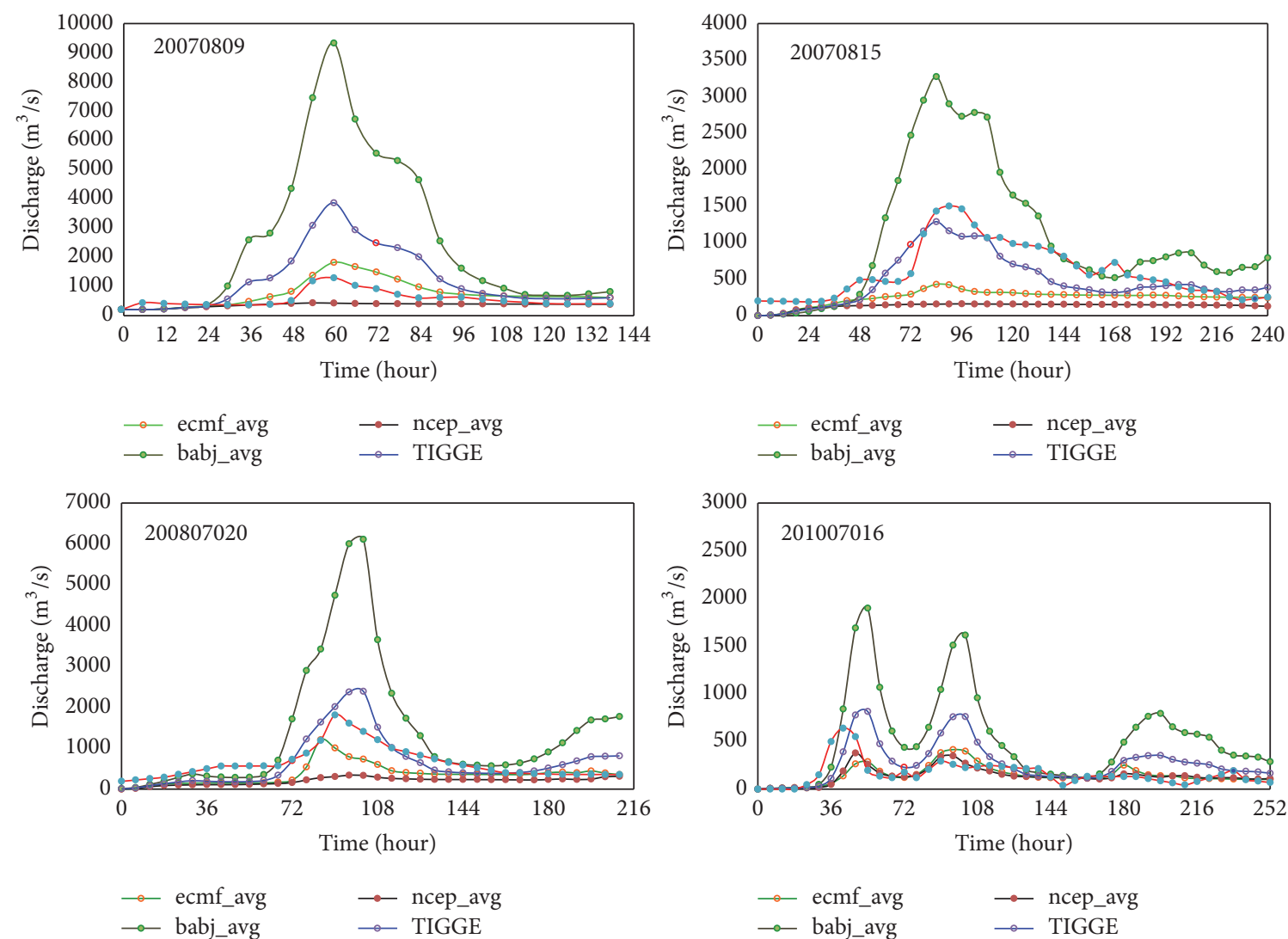

FIGURE 4: Comparison of the superensemble forecasted discharges from equal weight superensemble with observations (red lines with dots).
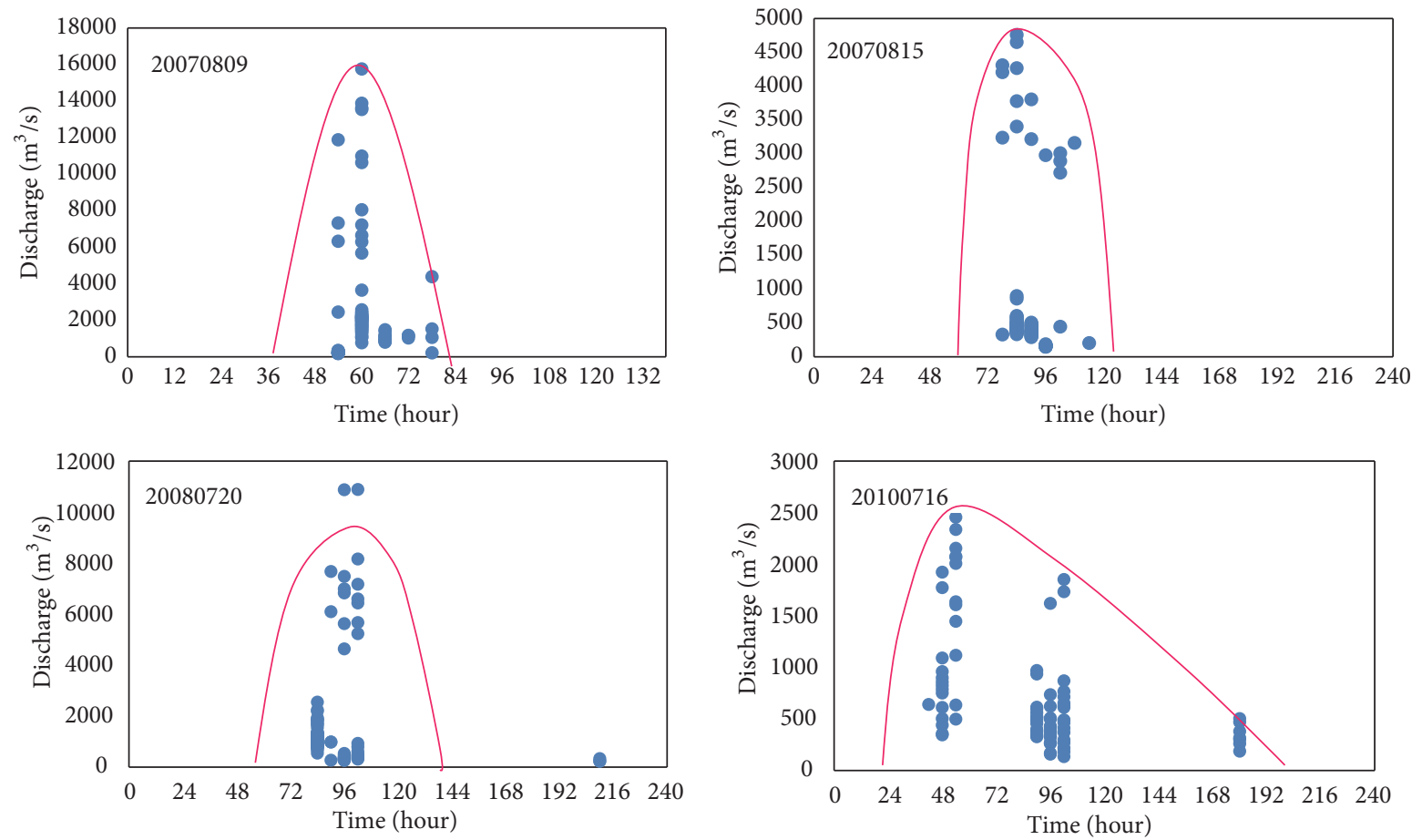

FIGURE 5: The scatter plot between the peak discharge (vertical coordinate) and its occurrence (horizontal coordinate) forecasts from superensemble members. The inverse U-shaped envelope curve reflects the joint probability distribution of the peak discharge and its occurrence forecasts. 

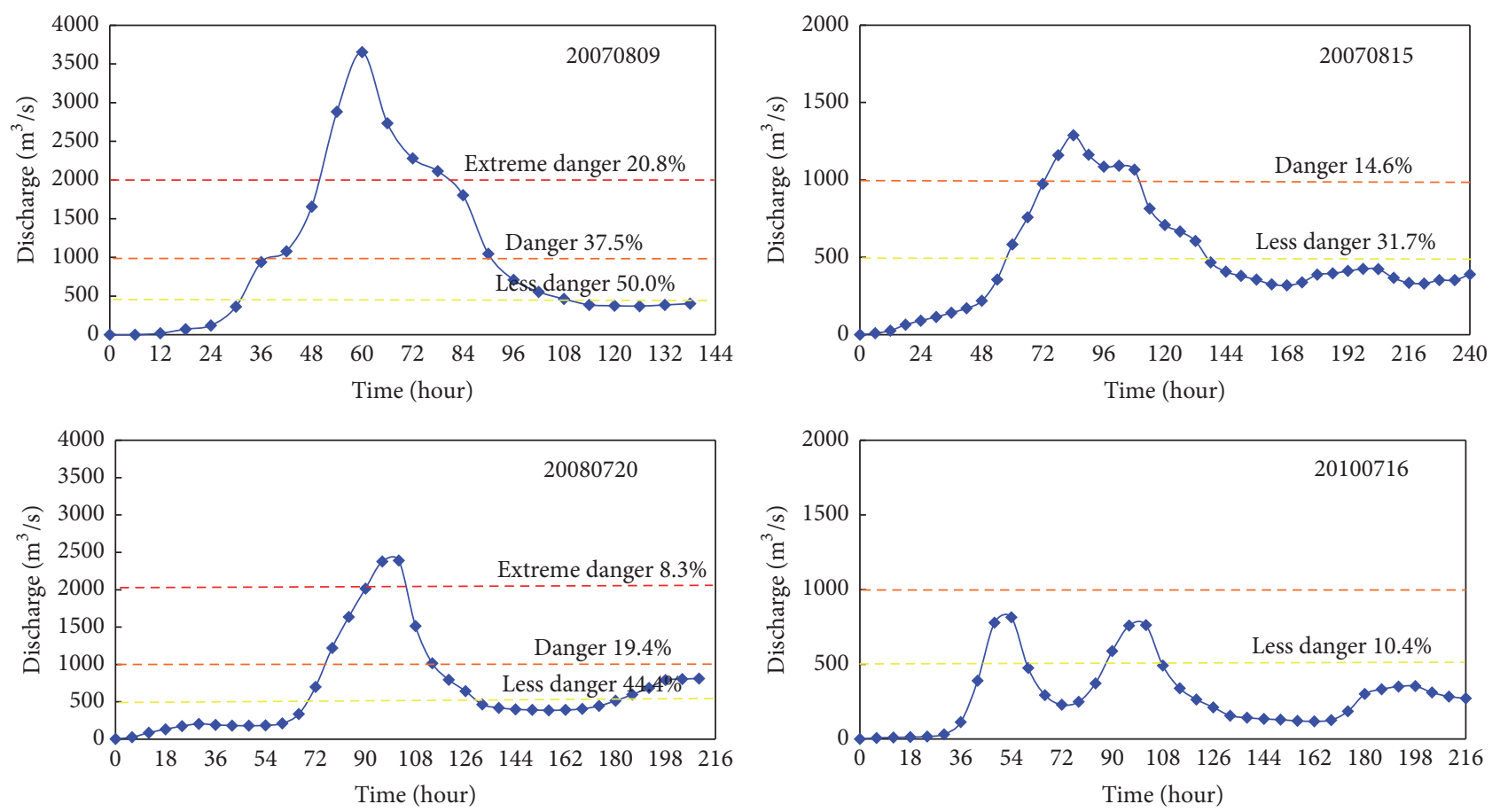

FIGURE 6: Flood warning probability from superensemble system.

20100716 events from superensemble forecast. All the events show an inverse "U" probability distribution or approximately a normal distribution except the 20100716 event. It can easily be obtained from Figure 5 that the occurrence of peak discharge mainly locates within the window zone/interval, and the probability is further calculated by the proportion of the members with peak discharge from all ensemble members. All the ensemble members forecasted similar occurrence of peak discharge; there is little difference among these three ensemble systems. The forecasted occurrence of peak discharge is close to the observations with forecast error less than 12 hours. For the 20100716 event, the peak discharge is relatively less than others, and there is more than one peak discharge. The precipitation for this event is not well predicted in all the ensemble systems, which causes large errors in forecasted discharge. Two main reasons are responsible for this: one is the large forecast errors of precipitation and the other one is hydrologic model itself which has unsatisfied performance for flood with a small discharge. For this event, the spread of the ensemble members in each model is relatively small, but large discrepancies exist among the models. The forecasted occurrence window of peak discharge differs, which makes it difficult for users to make decisions. For all these four events, the forecasts for large discharge are much better than that for small discharge. The superensemble of forecasted occurrence of peak discharge can easily be obtained from the probability distribution map of the peak discharge, which is one of the advantages of the superensemble.

Figure 6 shows the flood warning probability from superensemble system. $X$-axis represents the forecast time, and $Y$-axis represents the mean discharge of 85 members. The probability for three flood ratings ("less danger," "danger," and "extreme danger") is, respectively, calculated and considered by the ratio of the corresponding duration to total duration, which is from $0 \mathrm{~h}$ to the longest lead time at $6 \mathrm{~h}$ intervals. The 20070809 and 20080720 events have higher discharges, followed by the 20070815 event. The 20100716 event has the lowest discharges. For the 20070809 event, the superensemble forecasted probability for "less danger" (discharges greater than $500 \mathrm{~m}^{3} / \mathrm{s}$ ) is $50.0 \%$, for "danger" (discharges greater than $1000 \mathrm{~m}^{3} / \mathrm{s}$ ) is $37.5 \%$, and for "extreme danger" (discharges greater than $2000 \mathrm{~m}^{3} / \mathrm{s}$ ) is $20.8 \%$. It means, for more than $1 / 3$ of the time during this event, the discharges passing the outlet of Linyi catchment are over "danger" threshold. For more than $1 / 5$ of the time during this event, the discharges passing the Linyi catchment are over "extreme danger" threshold. The discharges in 20070815 event are lower, and the probability of reaching "extreme danger" threshold is only $14.6 \%$. The discharges in 20100716 event are the lowest, and the probability of reaching "less danger" threshold is only $10.4 \%$ and yet did not reach "danger" threshold. All above information are very useful references for decision-makers in local government and hydrological, meteorological, and agricultural offices. Due to various configuration of the models, the forecasted precipitation is significantly different, which further leads to tremendous discrepancies on forecasted discharges. However, the occurrence of the peak discharge and the probability of flood are well predicted. Compared with deterministic forecast, flood forecasting based on TIGGE and TOPX is able to provide more valuable information and probability of risk and is a promising approach. 


\section{Summary and Discussions}

In this paper, flood forecasting using distributed hydrologic model TOPX coupled with TIGGE ensemble precipitation data is documented. TIGGE data from ensemble forecast products at ECMWF, NCEP, and CMA are used to drive TOPX to make flood forecast for 20070809, 20070815, 20080720, and 20100716 events over Yishu River catchment. The results show the coupled model can successfully simulate the discharges during the events. The peak discharges as well as the occurrence of the peak discharge can be well predicted, but large discrepancies exist between the models. The CMATOPX forecasted higher discharges, while the NCEP-TOPX forecasted lower discharges. The ECMWF-TOPX forecasts are in between the other two models and are closest to the observation. According to the superensemble forecast of the occurrence of the peak discharge and the probability of flood, the TIGGE-TOPX coupled model can successfully predict the occurrence time of the peak discharge and probability of flood, which is the primary basis for decision-makers to make a decision.

This initial approach aims to build a basic framework of flood forecast model using TOPX model coupled with TIGGE precipitation data. The preliminary results are encouraging, but some issues need further investigation and research. Firstly, TIGGE dataset starts from year 2007, and only discharges data during years 2007-2010 are used in this study. Because of the limited data, only four flood events are simulated with TIGGE data as input. Though the results are encouraging, more flood events are needed to verify the performance of the coupled model, especially for the event in dry year. The hydrologic processes over nonhumid area are also not well simulated in TOPX. Second, accuracy of the precipitation forecast directly impacts the accuracy of the flood forecast. There are large forecast errors in all the global ensemble forecast models. Third, ensemble precipitation forecasts from three global NWP centers (ECMWF, NCEP, and CMA) are used in this study. The forecasted precipitation from these three NWP centers varies significantly. Currently, equal weight averaging is adopted to obtain the superensemble mean. To attribute different weight to each forecast center according to their forecasts biases is the next topic we should focus on and put efforts into.

\section{Competing Interests}

The authors declare that there is no conflict of interests regarding the publication of this paper.

\section{Acknowledgments}

The current research is supported financially by the Basic Research Program of Youth Fund Project of Jiangsu Province (BK20141001), China Special Fund for Meteorological Research in the Public Interest (GYHY201406021), Huaihe River Basin Meteorological Open Research Fund (HRM201205), National Natural Science Foundation of China (41275030), and Anhui Provincial Natural Science Foundation (1508085MD64).

\section{References}

[1] Q. Wu, "Review of 20th century floods," Journal of Catastrophology, no. 2, pp. 62-69, 2002 (Chinese).

[2] E. Roulin and S. Vannitsem, "Skill of medium-range hydrological ensemble predictions," Journal of Hydrometeorology, vol. 6, no. 5, pp. 729-744, 2005.

[3] E. Roulin, "Skill and relative economic value of mediumrange hydrological ensemble predictions," Hydrology and Earth System Sciences, vol. 11, no. 2, pp. 725-737, 2007.

[4] J. Komma, C. Reszler, G. Blöschl et al., "Ensemble prediction of floods-catchment non-linearity and forecast probabilities," Natural Hazards Earth System Sciences, no. 7, pp. 431-444, 2007.

[5] J. Thielen, J. Bartholmes, M. H. Ramos et al., "The European Flood Alert System-part 1: concept and development," Hydrology and Earth System Science Discussions, no. 5, pp. 257-287, 2008.

[6] F. Pappenberger, J. Bartholmes, J. Thielen, H. L. Cloke, R. Buizza, and A. de Roo, "New dimensions in early flood warning across the globe using grand-ensemble weather predictions," Geophysical Research Letters, vol. 35, no. 10, Article ID L10404, 2008.

[7] Y. He, F. Wetterhall, H. L. Cloke et al., “Tracking the uncertainty in flood alerts driven by grand ensemble weather predictions," Meteorological Applications, vol. 16, no. 1, pp. 91-101, 2009.

[8] Y. He, F. Wetterhall, H. Bao et al., "Ensemble forecasting using TIGGE for the July-September 2008 floods in the Upper Huai catchment: A Case Study," Atmospheric Science Letters, vol. 11, no. 2, pp. 132-138, 2010.

[9] Y. Peng, W. Xu, P. Wang, and F. F. You, "Food forecasting by coupling TIGGE ensemble precipitation forecast," Journal of Tianjin University, vol. 48, no. 2, pp. 177-184, 2015 (Chinese).

[10] H.-J. Bao, L.-N. Zhao, Y. He et al., "Coupling ensemble weather predictions based on TIGGE database with Grid-Xinanjiang model for flood forecast," Advances in Geosciences, vol. 29, pp. 61-67, 2011.

[11] H. Bao and L. Zhao, "Flood forecasting over Huai River catchment based on ensemble forecast," Journal of Hydraulic Engineering, vol. 43, no. 2, pp. 216-225, 2012 (Chinese).

[12] B. Yong, Development of a land-surface hydrologic model TOPX and its coupling study with regional climate model RIEMS [Ph.D. thesis], School of Geographic and Oceanic Science, Nanjing University, Nanjing, China, 2008 (Chinese).

[13] Y. Shao, Assimilation of doppler radar precipitation with the improved regional climate model RIEMS [Ph.D. thesis], School of Geographic and Oceanic Science, Nanjing University, Nanjing, China, 2010 (Chinese).

[14] G.-Y. Niu, Z.-L. Yang, R. E. Dickinson, and L. E. Gulden, "A simple TOPMODEL-based runoff parameterization(SIMTOP) for use in global climate models," Journal of Geophysical Research Atmospheres, vol. 110, no. 21, Article ID D21106, 2005.

[15] R. Zhao, Hydrologic Models: Xinanjiang Model and Shanbei Model, Hydraulic and Electric Power Press, Beijing, China, 1984 (Chinese). 

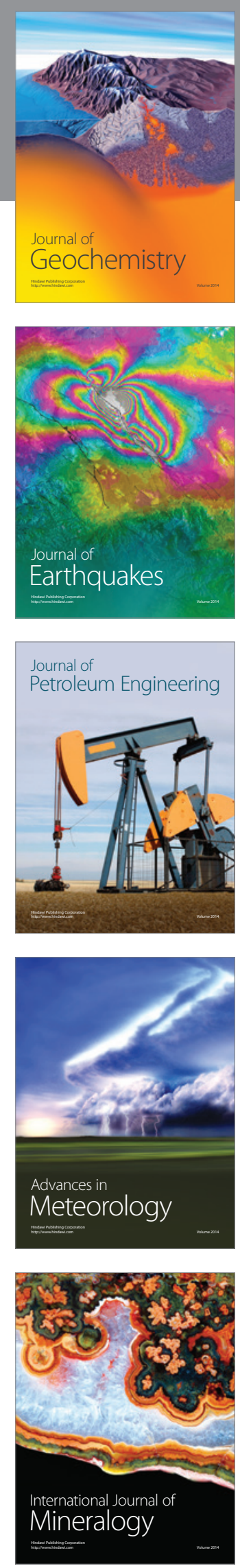
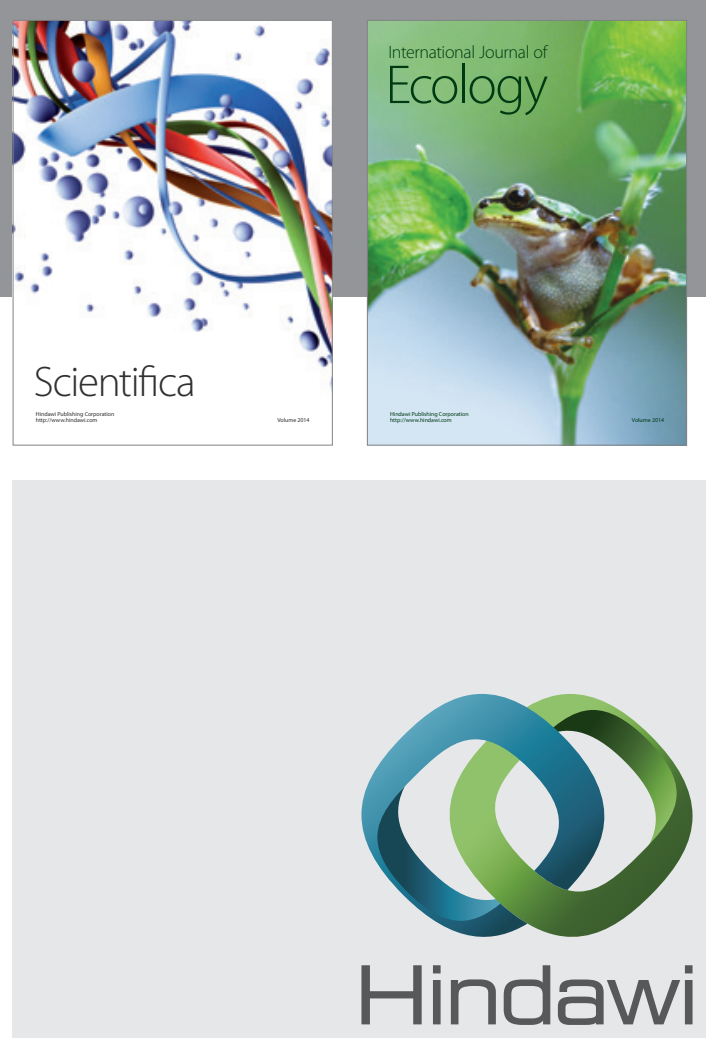

Submit your manuscripts at

http://www.hindawi.com
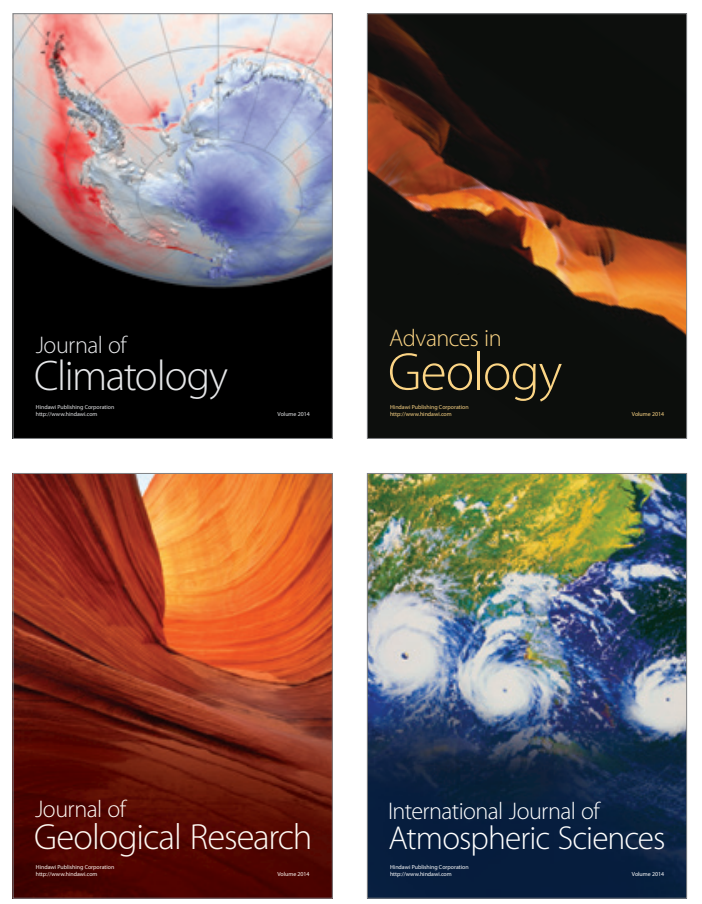

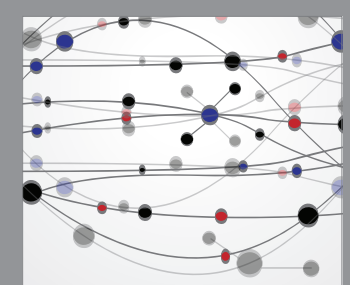

The Scientific

\section{World Journal}
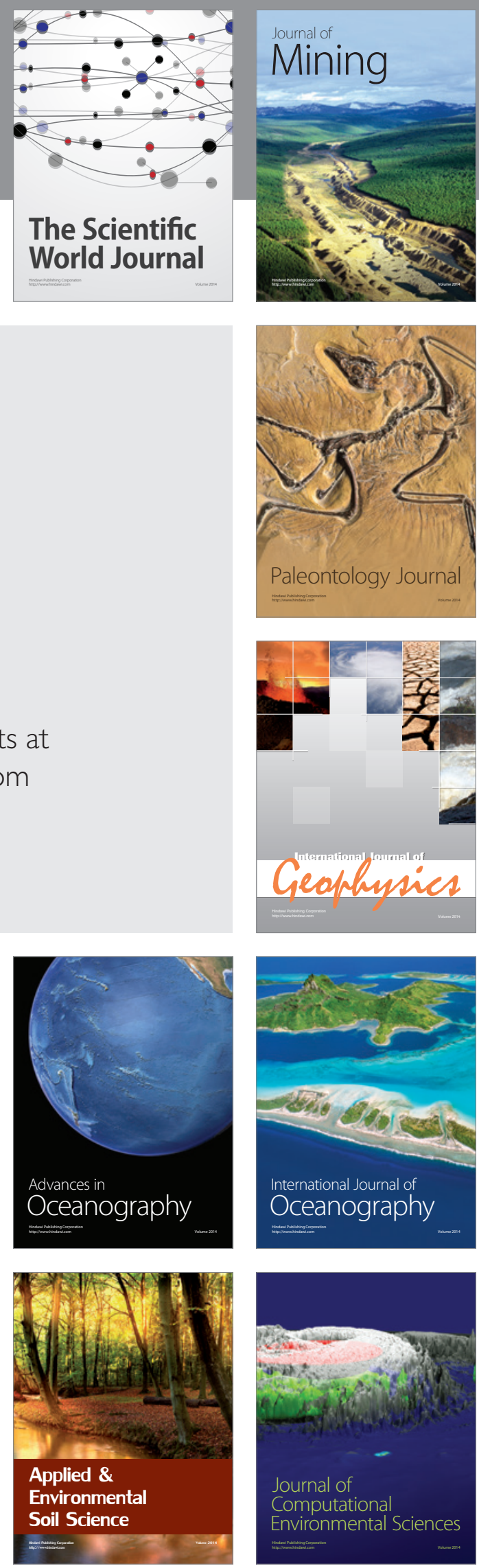